\title{
O texto dramático e a cena teatral: elementos de análise a partir de Patrice Pavis
}

\author{
Fabiano Tadeu Grazioli ${ }^{1}$ \\ Departamento de Linguística, Letras e Artes, \\ Universidade Regional Integrada do Alto Uruguai e das Missões, Erechim, RS, Brasil \\ Faculdade Anglicana de Erechim, Erechim, RS, Brasil
}

Resumo: $O$ artigo recupera aspectos relevantes na análise de textos dramáticos e da encenação teatral, tendo em vista a proposta de Patrice Pavis em importante estudo publicado no Brasil: A análise dos espetáculos: teatro, mímica, dança, teatro-dança, cinema (2011). No início, tratamos das duas visões do espetáculo apontadas por Pavis (2011), a saber, a visão "textocentrista" e a visão "cenocentrista", a primeira calcada no texto dramático, a segunda na encenação teatral. Na sequência, exploramos um denominador teórico que Pavis (2011) sugere tanto para a análise do texto dramático, quanto para a encenação teatral: o levantamento da ação e dos actantes, das estruturas do espaço, do tempo, do ritmo e da articulação e o estabelecimento da fábula. Para isso, partimos da referida publicação em direção a publicações anteriores (PAVIS, 2007, 2008), que nos permitem ampliar os conceitos para melhor desenvolvê-los, em interface com estudos já existentes sobre as temáticas. $\mathrm{O}$ trabalho aponta para a efetiva correlação entre os elementos sugeridos por Pavis (2011), que se tornam importantes no estabelecimento de critérios para o estudo e a leitura do texto dramático.

Palavras-chave: Dramaturgia; Texto dramático; Patrice Pavis.

Title: The Dramatic Text and the Theater Scene: Elements of Analysis Based on Patrice Pavis

Abstract: This article presents relevant aspects of the theatrical stage and dramatic texts analysis, which are based on Patrice Pavis' orientation and his important study published in Brazil: $A$ análise dos espetáculos: teatro, mímica, dança, teatro-dança, cinema (Spectacles analysis: theater, mime, dance, theater-dance, cinema) (2011). First, the two spectacle perspectives are the "textocentrist" and "cenocentrist" concepts, the former is related to dramatic text and it is seen as a guide and the second one is focused on theatrical performance, so the scene is more important than the text itself. Then, a theoretical aspect is explored in which Pavis (2011), suggests either for dramatic text analysis or for theatrical performance: the observation of the action and its agents, the space structures, time, rhythm and the fable articulation and performance. Thus, we start from the aforementioned publication towards previous publications (PAVIS, 2007, 2008) to improve concepts for developing them better in relation to studies that already exist about these themes. The study shows an effective correlation between the elements suggested by Pavis (2011), which have become important when it comes to establishing criteria for studying and reading the dramatic text.

Keywords: Dramaturgy; Dramatic text; Patrice Pavis.

\footnotetext{
${ }^{1}$ Doutor e Mestre em Letras pelo Programa de Pós-Graduação em Letras da Universidade de Passo Fundo. Professor da Universidade Regional Integrada do Alto-Uruguai e das Missões, campus de Erechim e da Faculdade Anglicana de Erechim. ORCID: https://orcid.org/0000-0002-3860-6767 E-mail: tadeugraz@yahoo.com.br
} 


\section{Introdução}

Na bibliografia em língua estrangeira, que já temos traduzida para o português, os estudos voltados para a visão "textocentrista" ou para a visão "cenocentrista" do espetáculo (com essas ou outras terminologias), bem como os textos dramáticos com um enfoque mais literário ou menos literário recebem páginas e mais páginas nas pesquisas relacionadas a representações cênicas mesmo ou dos textos dramáticos. A abordagem inicial deste artigo de apresenta brevemente a visão "textocêntrica" e a visão "cenocêntrica" do espetáculo, com destaque para a primeira, uma vez que nos interessa, nesses estudos, os aspectos teóricos que possam favorecer o estudo da dramaturgia escrita, como as considerações de Luiz Fernando Ramos (1999) sobre rubricas.

Após apresentar as duas visões a partir de Pavis $(2012$, 2008), nosso texto avança e explora um denominador que o estudioso francês lança para a análise tanto do espetáculo, quanto do texto dramático: a) focalizar a determinação da ação e dos actantes; b) as estruturas do espaço, do tempo e do ritmo; c) a articulação e o estabelecimento da fábula. É a partir desse ponto que nossa proposta passa a ampliar e discutir tais elementos, com a ajuda pontual de outras publicações do autor, em especial o Dicionário de teatro (PAVIS, 2007) e também com a leitura e aproveitamento de outras publicações sobre as temáticas levantadas, como a tese de doutoramento de Daniel Furtado Simões da Silva (2013), da qual recolhemos informações sobre os actantes; o estudo de Ramon Santana de Aguiar (2008) sobre o espaço dramático; e a dissertação de Mestrado em Artes Cênicas de Clarice Lopes Mendes (2009), da qual nos aproveitamos para falar sobre o ritmo e o sentido do texto teatral.

\section{Visão “textocentrista” e visão “cenocentrista” do espetáculo}

A análise dos espetáculos: teatro, mímica, dança, teatro-dança, cinema, de Patrice Pavis (2011), não é uma obra (só) sobre o texto dramático, e sim sobre a linguagem cênica que envolve os diferentes espetáculos, principalmente o teatral. Pavis (2011) repassa, junto ao leitor, todos os elementos que compõem os espetáculos cênicos, desde o trabalho do ator em cena até o uso da maquiagem. Dentre os elementos que podemos inserir entre esses citados, que podem ser considerados polarizadores (quase que opostos), Pavis (2011) inclui a ação, o tempo, o espaço, voz, o ritmo, o texto impostado, o figurino, a iluminação, além de 
abordagens como a psicológica e psicanalítica, a sociológica, entre outros temas; e claro, não deixa de fora o texto dramático. Mas o texto dramático é tomado como um elemento da linguagem teatral, já que, como dissemos, a intenção do autor francês é oferecer ao leitor um panorama de como se realiza a análise de um espetáculo, tendo em vista a linguagem cênica e a articulação dos elementos que a compõem. Nessa tarefa, o estudioso dedica um espaço ao texto dramático e o analisa considerando o seu papel na construção da linguagem cênica, que envolve aqueles espetáculos que se projetam a partir de um texto.

Sabendo que nem sempre o texto dramático é o ponto de partida para um espetáculo, especialmente na contemporaneidade, em que encontramos muitas experiências cênicas que não dependem de um texto para a sua existência, Pavis (2011) divide os espetáculos em duas categorias: os que possuem uma visão "textocentrista" da encenação e os que possuem uma visão "cenocentrista". Na primeira categoria, não é difícil deduzir que se trata de casos em que a encenação

decorre diretamente do texto: decorre no sentido em que a cena atualiza elementos contidos no texto. É até mesmo esse, no fundo, o verdadeiro sentido da expressão "encenar um texto": coloca-se em cena, elementos que se acabou de extrair do texto, depois de tê-lo lido. O texto é então concebido como uma reserva, ou até mesmo o depositário de sentido que a representação tem como missão extrair e expressar como se extrai o suco (cênico) da cenoura (textual). (PAVIS, 2011, p. 190, grifos do autor).

De acordo com o autor, essa visão é tanto dos filólogos - "[...] para quem o texto dramático é tudo e a cena uma simples ilustração, um assunto retórico para temperar o texto." (PAVIS, 2011, p. 190)-, quanto dos numerosos teóricos do teatro, dentre os quais Pavis inclui os semiólogos, conjunto do qual cita Anne Ubersfeld, Alessandro Serpieri, Erika FischerLichte. Pavis (2011) destaca que não se trata de saber de modo absoluto qual é o primeiro elemento concebido (o texto ou a cena) e qual é o soberano no espetáculo, pois as respostas variam segundo os momentos históricos escolhidos para a análise. A questão, então, "[...] é saber se em um espetáculo que contém um texto (do qual não se sabe se ele preexistia ou não ao trabalho teatral), um elemento decorre do outro e precisa assim do outro para se determinar". (PAVIS, 2011, p. 190). Isso porque, na visão "textocentrista", os estudiosos acreditam na relação indissolúvel entre texto dramático e a cena criada a partir dele. Pavis (2011, p. 191) explica mais detalhadamente a concepção dessa visão: 
O texto não é descrito em sua enunciação cênica, ou seja, como prática da cena, mas como referência absoluta e imutável, como pivô de toda a encenação. Ao mesmo tempo, o texto é declarado incompleto, já que necessita da encenação para tomar seu sentido. Tais visões filológicas têm todas em comum uma visão normativa e derivativa da encenação: esta não pode ser arbitrária, ela deve servir o texto e se justificar para uma leitura correta do texto dramático. Pressupõe-se que o texto e a cena estão ligados e que foram concebidos um em função do outro: o texto em vista de uma futura encenação, ou pelo menos de um modo dado de atuação; a cena pensando naquilo que o texto sugere para sua espacialização.

Nota-se, nas palavras do autor francês, que a medida da encenação, na visão "textocentrista" do espetáculo, é o texto dramático. Deriva dele todo o sistema que envolve os demais elementos cênicos e, ainda, a encenação teatral é pulverizada pelo texto, cabendo a ela uma função de atualização, por meio dos elementos de sua linguagem, de aspectos contidos no texto dramático, tanto nas indicações cênicas, quanto nos diálogos. Do fragmento de Pavis (2011), também depreendemos que as coordenadas da própria encenação, no sentido da linguagem cênica a ser assumida pelo encenador, encontram-se no texto. Tal visão aponta para os estudos de Luiz Fernando Ramos (1999), para quem as rubricas de determinados textos dramáticos possuem um potencial instaurador de uma certa materialidade cênica e também podem ser vistas como "[...] espelho de um estilo particular de engendrar espetáculos, e como índice de uma poética cênica específica". (RAMOS, 1999, p. 52). Para demonstrar a presença daquilo que chama de "poética de cena" nas rubricas, o autor analisa minuciosamente a dramaturgia de Samuel Beckett e declara: "Em sua escrita dramática [...] a rubrica será tão importante quanto o diálogo, pois refere-se a uma desejada ocupação tempo-espacial do palco que se revelará imprescindível a cada espetáculo efetivo que se apresente. (RAMOS, 1999, p. 61).

Ramos (1999), embora não explore os estudos de Pavis (2011) e nem dos filólogos e dos semiólogos citados pelo autor francês, também considera o elemento que impulsiona a linguagem teatral a ser empreendida no palco. Segundo Ramos (1999), as chamadas indicações cênicas têm, em Beckett, desde o primeiro texto, peso fundamental na sua dramaturgia, mas já são, desde o início do conjunto de sua obra, imprescindíveis na transposição deste texto para o palco. Em relação à não observação das indicações cênicas da peça Esperando Godot, o pesquisador declara: “Quem ignora completamente as rubricas da peça deixa de encenar Esperando Godot, de Samuel Beckett, já que mais do que sugerir ações acessórias, algumas rubricas indicam ações fundamentais para que se consume o arco de ação 
proposto pelo dramaturgo". (RAMOS, 1999, p. 65, grifo do autor). A garantia da perpetuação da obra de Beckett não está, segundo Ramos (1999), na manutenção dos diálogos, e sim na observação das coordenadas lançadas pelas rubricas. A "poética de cena" que irá receber e contextualizar os diálogos deverá ser respeitada, sob pena de, se assim não for, extinguir-se a essência da obra do dramaturgo. As considerações de Ramos (1999) não estão a apontar a existência de mais um conjunto de peças puramente literárias, como muitos críticos classificam aquelas peças escritas com recursos literários em excesso e difíceis de levar à cena. Elas estão a aproximar certo tipo de dramaturgia à visão "textocentrista" do espetáculo teatral, por isso as revisamos.

Ao discorrer sobre a visão "cenocentrista", Pavis (2011) deixa transparecer, sem constrangimentos, a sua visão de que a cena é um elemento independente do texto dramático e que este não passa de um elemento, tal como os demais elementos que constituem a linguagem cênica. Afirma ele:

Seria preciso, para acabar com essas visões filológicas ter a radicalidade de um esteta como Thies Lehmann, para quem "a encenação não é uma prática artística estritamente imprevisível pela perspectiva do texto?" Tal posição radical nega qualquer ligação de causa e efeito entre o texto e a cena, atribuindo à encenação o poder de decidir soberanamente suas escolhas estéticas. (PAVIS, 2011, p. 191, grifo do autor.)

Nessa perspectiva, “[...] o texto não se beneficia mais de um estatuto de anterioridade ou de exclusividade: é apenas um dos materiais de representação e não centraliza nem organiza os elementos não verbais". (PAVIS, 2011, p. 191). Em um estudo que se encontra na obra O teatro no cruzamento de culturas, Pavis $(2008$, p. 24) retoma essa discussão ao afirmar que

Toda semiologia teatral que pressupõe, a priori, possuir o texto dramático uma teatralidade que se trata de extirpar do texto a qualquer custo afim de exprimi-lo no palco - ou seja, uma matriz teatral -, de ver uma partitura que, quando muito, dá ao texto dramático uma existência visando uma futura representação, parece-nos que se trata de reduzir abusivamente a encenação a um mero decalque do texto e a estabelecer implicitamente que a encenação é a expressão do texto, que ele a contém implicitamente e, portanto, que existe apenas uma só e boa encenação previamente contida no texto.

Nota-se que Pavis (2008) reclama dos estudos que buscam confrontar texto dramático e encenação teatral, no sentido de encontrar as coordenadas da segunda no primeiro. De 
acordo com ele, está clara a circunstância de que texto dramático e encenação teatral são elementos independentes, e que a atualização do texto dramático deve investir em uma linguagem calcada na encenação teatral, que é majoritária e independente, frente à dramaturgia escrita. Muitos encenadores, de fato, são adeptos do processo descrito por Pavis (2008), e seu processo de encenação teatral é regido por normas próprias, que dizem respeito à linguagem cênica e não à literatura dramática. Contudo, é o próprio autor que levanta um questionamento sobre a validade da metodologia de encenação para todos os textos:

[...] para encenações de textos cuja leitura e conhecimento é por assim dizer, inevitável (sejam esses textos conhecidos ou simplesmente baseados em personagens e situações dificilmente ignoráveis), a tese de Lehmann é mais dificilmente sustentável, pois o espectador não deixará de se interrogar sobre a relação entre a prática artística e o texto, seja apenas para se perguntar como a cena pode a esse ponto ignorar o que sugere para nós o texto. (PAVIS, 2011, p. 191).

Os textos "baseados em personagens e situações dificilmente ignoráveis", citados pelo autor, acrescentamos, são desdobramentos da dramaturgia conhecida para a além dos séculos e que constituem experiências novas, tomando, por exemplo, um personagem já construído e oferecendo a ele nova dramaturgia e novo espetáculo. Como exemplos, podemos citar Madame Macbeth, da argentina Griselda Gambaro, que recria a tragédia shakespeariana sob o ponto de vista de Lady Macbeth, monólogo encenado no Brasil em 2007. Quem viveu Lady Macheth na montagem foi Marília Gabriela, num sucesso de público e crítica. Medeia é outro monólogo que surge como desdobramento de uma dramaturgia já conhecida, este com texto assinado e encenado pela Téspis Cia. de Teatro, a partir da tragédia de Eurípides, um espetáculo ritualístico que conservou a tônica da tragédia em questão: o amor transformado em ódio sobre-humano. O espetáculo estreou em 2002, com Denise da Luz no papel de Medeia, e faz parte do repertório da referida companhia de teatro catarinense.

O último fragmento de Pavis (2008) transcrito nos remete à contradição de o texto e sua história na dramaturgia apontarem, conhecidamente, para uma direção e a encenação ignorar os propósitos do texto, suas montagens e estudos antecedentes, como certa vez presenciamos na encenação do Auto da Compadecida, de Ariano Suassuna: Nossa Senhora Aparecida foi transformada, por opção dos encenadores, em uma miss, colocando em choque a concepção do texto de Suassuna e a montagem que dele derivou. 
Tratando das especificidades dos textos dramáticos, Pavis (2011) apregoa que nem sempre os textos escritos com características dramatúrgicas são aqueles utilizados para a cena dramática. "Parece assim vetado limitar os textos para a cena a um tipo estabelecido de escrita dramática". (PAVIS, 2011, p. 194). Isso acontece porque, segundo ele, todos os tipos de texto podem se transformar em um espetáculo teatral. O caráter específico da escrita teatral parece mutável e seria muito hábil "[...] aquele que definisse essa escritura especificamente dramática trans-histórica e universal" (PAVIS, 2011, p. 194), ou seja, construísse uma definição de escrita dramática que ultrapassasse os tempos históricos e a produção dramatúrgica de todos os continentes e países.

A única coisa que se pode afirmar é que cada momento histórico e cada prática dramatúrgica cênica que lhe corresponde possuem seus próprios critérios de dramaticidade (maneira de armar um conflito) e de teatralidade (maneira de utilizar a cena). Em vez de tentar uma definição fenomenológica universal e abstrata da especificidade da escrita dramática, melhor seria, por conseguinte, tratar historicamente cada caso particular, quer dizer, examinar como o texto foi concebido em função de uma certa prática da língua e da cena e quais procedimentos dramatúrgicos se encontram valorizados. (PAVIS, 2011, p. 194).

Os critérios de dramaticidade, ou seja, as várias maneiras de armar um conflito, de construir um texto dramático são os que nos importam de perto nessa escrita. De conhecimento desses critérios, o crítico pode passar a examinar como o texto foi concebido tendo em vista certas práticas da língua, principalmente as literárias, que atuaram na construção e legitimação de determinada escrita dramática. Também nos importam outras práticas da língua, aquelas que legitimam uma maneira de escrever dramaturgia que tenha apontado os caminhos da produção de textos dramáticos para a infância nos últimos. Pavis (2011) sugere, tendo em vista o conhecimento histórico da produção e da recepção do texto, que se levantem, tanto para o texto quanto para a cena, os seguintes aspectos: a determinação da ação e dos actantes; as estruturas do espaço, do tempo e do ritmo; a articulação e o estabelecimento da fábula. É a partir deles que organizamos nossa escrita, a partir de agora. 


\section{A ação e os actantes}

O primeiro passo da análise dramatúrgica é determinar a ação, ou seja, "[...] a sequência de acontecimentos cênicos essencialmente produzidos em função do comportamento das personagens, [...] o conjunto de processos de transformações visíveis em cena, e no nível das personagens, o que caracteriza suas modificações psicológicas ou morais". (PAVIS, 2007, p. 2). Na complexa tarefa de definir "ação", em seu Dicionário de teatro, Pavis (2007) é pontual quando afirma que se trata do "[...] elemento transformador e dinâmico que permite passar lógica e temporalmente de uma para outra situação. Ela [a ação] é a sequência lógico-temporal das diferentes situações". (PAVIS, 2007, p. 3).

Trata-se também de determinar os "actantes", as “[...] entidades gerais, nãoantropomorfas e não-figurativas (exemplo: a paz, Eros, o poder político). Os actantes só tem existência teórica e lógica dentro de um sistema de lógica da ação ou da narratividade". (PAVIS, 2007, p. 9). Quando traz a definição transcrita de actantes, o autor está apresentando a teoria dos níveis de existência da personagem, dentro do verbete "Modelo actancial". O nível dos actantes é o nível II.

Aos personagens, no sentido tradicional, cabe o nível III. Importante não confundir os actantes com os personagens propriamente ditos, nem com os papeis, que constituem um nível intermediário entre II e III e são "[...] entidades figurativas, animadas, mas genéricas e exemplares, (ex.: o fanfarrão, o pai nobre, o traidor)". (PAVIS, 2007, p. 9). O papel, na dramaturgia e na encenação, participa, segundo Pavis (2007), ao mesmo tempo da estrutura narrativa profunda e da superfície textual. Daniel Furtado Simões da Silva (2013), em sua tese de doutoramento em Artes, intitulada $O$ ator e o personagem: variações e limites no teatro contemporâneo, lembra-nos que "[...] o conceito de actante extrapola tanto o conceito de personagem teatral como o da pessoa do ator e o(s) papel(is) que este assume em cena; [...] é mais amplo que ambos, tendo sido cunhado para servir a uma análise textual [...]." (SILVA, 2013, p. 128, grifo do autor). A afirmação do autor conecta-se aos conceitos extraídos do Dicionário de Pavis (2007) e, ainda, não nos deixa esquecer que os actantes existem para favorecer uma análise textual, ou seja, a análise dramatúrgica, como bem lembrou Pavis (2007), quando afirmou que os actantes possuem existência teórica, muito embora sirvam também para a análise da encenação teatral. 
Trouxemos à nossa escrita definições próximas à dos actantes para podermos afirmar, em oposição a elas, que se trata da substância que recende de cada personagem, quase que a condensação de suas forças matrizes dentro do texto dramático. Assim, um actante pode ser representado por vários atores, ou um personagem pode encobrir dois actantes. No primeiro caso, Pavis (2007) cita como exemplo, Mãe coragem, de Bertolt Brecht, na qual o actante "sobreviver" cabe a diferentes personagens: Mãe coragem, o cozinheiro, os soldados, os capitães. Como exemplo do segundo caso, Pavis (2007) cita outra peça de Brecht, A Alma Boa de Sé-Tsuan, na qual um personagem encobre dois actantes diferentes: ser humano e ter lucro a qualquer preço.

\section{O espaço, o tempo e o ritmo}

Localizar as estruturas do espaço, do tempo e do ritmo são o segundo aspecto que Pavis (2012) sugere na análise da dramaturgia e da cena. Para tratarmos da estrutura do espaço, recorremos a uma explicação de Pavis (2007) que elucida esse componente do texto dramático e da encenação teatral de modo didático, a explicar as diferenças básicas entre espaço dramático e espaço cênico². O primeiro "[...] é o espaço dramatúrgico do qual o texto fala, espaço abstrato e que o leitor ou o espectador deve construir pela imaginação (ficcionalizando)." (PAVIS, 2007, p. 132, grito do autor). Já o segundo “[...] é o espaço real do palco onde evoluem os atores, quer eles se restrinjam ao espaço propriamente dito da área cênica, quer evoluam no meio do público". (PAVIS, 2007, p. 132). Relacionado os espaços em questão, Pavis (2007), afirma que

Espaço dramático opõe-se a espaço cênico (ou espaço teatral). Este último é visível e se concretiza na encenação. O primeiro é um espaço construído pelo espectador ou pelo leitor para fixar o âmbito da evolução da ação e das personagens; pertence ao texto dramático e só é visualizado quando o espectador constrói imaginariamente o espaço dramático. (PAVIS, 2007, p. 135 , grifos do autor).

O espaço dramático pode ultrapassar as indicações cênicas ou as construções cenográficas que remetem o leitor/espectador a um espaço específico. Não se trata somente

\footnotetext{
${ }^{2} \mathrm{O}$ autor também faz referência ao espaço cenográfico, espaço lúdico, espaço textual e espaço interior. Nos furtamos desses conceitos por acreditarmos que o espaço dramático e o espaço cênico já trazem elementos suficientes para relacionarmos a estrutura do espaço aos textos dramáticos.
} 
ou exatamente do cenário construído para a cena, ou do espaço sugerido pelas rubricas, seria fácil demais depreender o seu significado no texto ou no espetáculo teatral se assim o fosse. Tal espaço pode ser sugerido em pequena dose pelas rubricas e pela cenografia, mas se trata de um elemento mais amplo e mais complexo na configuração do texto e da encenação teatral.

Ramon Santana de Aguiar (2008) também tratou desse tema:

O espaço dramático é proposto ao espectador, no jogo dramático realizado pelos personagens, suas ações e suas relações. Na construção ficcional do espaço dramático, o espectador extrapola, no caso do teatro, a cenografia e adentra no universo físico e temporal dos personagens e suas evoluções ao longo da trama. No caso de São Gonçalo do Bação, no texto $A$ saga baçônica, pode-se considerar as alusões à fundação do distrito mergulhada no tempo e nas relações históricas daquele período como exemplos de indicações para a construção mental do espaço dramático. Em relação ao texto Dolores é a véia, as relações sugeridas entre seus moradores, o rádio e suas interpretações de mundo. Já no texto Derrama lá, entorna cá, como o próprio título já sugere, as implicações políticas de um distrito rural de Vila Rica no período do Brasil colônia. (AGUIAR, 2008, p. 221, grifos do autor).

Os exemplos de Aguiar (2008) referem-se a textos dramáticos de autoria coletiva do grupo São Gonçalo do Bação, da comunidade rural de mesmo nome, do município mineiro de Itabirito. Em sua colocação e exemplificação, fica clara a premissa de que tratávamos: o espaço dramático ultrapassa cenários e (acrescentamos) indicações cênicas, e surge como um espaço potencial de imaginação e descoberta por parte do leitor/espectador, haja visto o desenrolar da ação, o envolvimento dos personagens entre si e com o momento histórico em que vivem etc. Dessas relações surge um espaço apreendido pela mente do leitor/espectador, pois ele não é somente lido ou visto, mas deduzido por aspectos como os que citamos. Como bem salienta Aguiar (2008, p. 222), “O espaço dramático está no âmbito da comunicação entre o autor e o leitor/ou público". Obviamente existem variações de natureza diversa (cores, formas, tamanhos, texturas etc.), já que o espaço dramático é estabelecido nas mentes a partir das experiências de quem assiste a encenação teatral ou lê o texto dramático.

O tempo é "[...] um dos elementos fundamentais do texto dramático e/ou da manifestação cênica da obra teatral, de sua representação (presentificação cênica)". (PAVIS, 2007 , p. 400). Esse estudioso, que aqui nos serve de base, trata do tempo de maneira ampla, e sua exposição parte de dois tipos de tempo. 0 tempo cênico é 
aquele da representação que está se desenrolando e aquele do espectador que está assistindo. Consiste num presente contínuo, que não para de desvanecer-se, renovando-se sem cessar. Essa temporalidade é ao mesmo tempo cronologicamente mensurável [...] e psicologicamente ligada ao sentido subjetivo da duração do espectador. (PAVIS, 2007, p. 400).

Quanto ao tempo dramático, Pavis (2007, p. 401) afirma que para percebê-lo é necessário "[...] apreender a maneira pela qual a intriga se organiza - escolhe e dispõem - os materiais da fábula, como ela propõe sua montagem temporal de certos elementos". É o tempo construído pelo dramaturgo e depois pela encenação, acrescentamos. Não se trata do tempo de duração da peça, a esta medida cabe ao tempo cênico, mas sim da articulação de unidade de tempo dentro da fábula. Esse tempo, o dramático, pode ser reconhecido na análise do texto escrito para o teatro, pois ali estão dispostos recursos necessários para a apreensão da organização, escolha e disposição do tempo. Já o tempo cênico é mais apropriado que se observe na representação, já que se trata de medi-lo em tempo contínuo durante a encenação teatral.

Talvez, pensando na leitura silenciosa que pode ser feita de um texto dramático, o tempo dessa leitura correspondesse ao tempo cênico. Contudo, na exposição que Pavis (2007) faz do tempo no teatro, tratando das "Modalidades do relacionamento das duas temporalidades", ele lista uma modalidade de tempo que tem importância na análise dramatúrgica de um espetáculo: o tempo histórico, “[...] uma realidade que se insere necessariamente no texto e na representação. Devido à multidão de suas temporalidades e de seu modo de produção, o teatro é sempre situado na história". (PAVIS, 2007, p. 402). Parece-nos fundamental, na prática da análise do texto dramático, situar a fábula em um determinado tempo histórico, já que as características desse tempo incidem em singularidades da narrativa dramática que se apresenta ao leitor.

Em relação ao ritmo, Pavis (2007) afirma que o estudo desse elemento ultrapassa o âmbito da literatura e do teatro: ele se fundamenta, na maior parte dos estudos, em bases fisiológicas, ou seja, ritmo cardíaco, respiratório ou muscular. Mesmo assim, o autor apresenta amplas formulações, em especial sobre o ritmo da encenação, enfatizando que o ritmo é de fundamental importância tanto para o trabalho vocal e gestual, como para o desenrolar do espetáculo. Para nossa escrita, importam de imediato as considerações voltadas ao texto dramático, tendo no trabalho vocal a sua manifestação: o que orientaria 
esta atividade pensada a partir do ritmo? Estaria o ritmo imbricado com a construção dos diálogos? Pavis (2007) trata como pretensão a possibilidade de encontrar um esquema rítmico previamente inserido no texto. Mais importante do que procurar o esquema rítmico a ser utilizado na encenação, na estruturação e na construção (seleção das palavras, elaboração dos diálogos, como marcas explícitas deixadas pelo dramaturgo no texto à disposição de serem atualizadas pelos atores), parece ser procurá-lo no sentido do texto. Segundo o pesquisador francês,

o ritmo do texto poético não se encontra acima do sentido sintáticosemântico, mas o constitui. É o ritmo que dá vida às partes do discurso; à disposição das massas dos diálogos, a figuração dos conflitos, a divisão dos tempos fortes e fracos, a aceleração ou a diminuição das trocas, tudo isso é uma operação dramatúrgica imposta pelo ritmo ao conjunto da representação. Procurar/encontrar um ritmo para o texto a ser representado é sempre procurar/encontrar um sentido. (PAVIS, 2007, p. 343 , grifo nosso).

Tendo presente a prática teatral contemporânea no Brasil, podemos afirmar que a procura do ritmo também passa pela compreensão do sentido, conforme podemos perceber neste depoimento do diretor Moacir Chaves, retirado da dissertação de Mestrado em Artes Cênicas de Clarice Lopes Mendes (2009, p. 152):

$\mathrm{O}$ ator tem que ter ritmo, tem que ter capacidade de distinção de sons, do som que ele produz, do som que ele quer produzir, para ver que sentido que isso produz na cena. Isso numa fala, numa peça... Tchekhov, Ibsen, Brecht, seja o que for. Eu estou produzindo um som numa fala. Esse som produz um sentido. Esse sentido não tem nada a ver com aquilo que eu acho. Você, inclusive, ator, acha. Então, vamos modificar o som que você está produzindo. Qual é o som que produz o sentido que você quer? Vamos imaginar isso, então?

O entrevistado coloca-se em conexão com o pesquisador francês quando declara que o ator deve procurar o ritmo que traduza o sentido que ele quer transmitir. Fora dessa circunstância, nem mesmo o ator é capaz de compreender o texto que está dizendo. $\mathrm{Na}$ análise do texto dramático, já que não temos condições de encontrar um esquema rítmico que subjaz ao próprio texto pela simples análise de sua construção, recorramos ao sentido do texto, caso seja do interesse do leitor de dramaturgia experimentar a cadência, as pausas, a impostação etc. que os diálogos carregam. Ao encontrar o sentido, o leitor/ator encontra o 
ritmo que precisa ser obedecido na fala do texto. Essa é antes, uma busca dramatúrgica, um mergulho no texto dramático à procura de um elemento articulador de sua encenação.

\title{
A fábula: articulação e estabelecimento
}

A articulação e o estabelecimento da fábula, último item do levantamento que Pavis (2011) sugere frente a um texto dramático e, principalmente, a uma encenação teatral, diz respeito à verificação de como a "[...] sequência de fatos que constituem o elemento narrativo de uma obra" (PAVIS, 2007, p. 157) se comporta em determinado texto ou encenação teatral. A fábula pode ser considerada como material anterior à composição da peça (como faziam os gregos, que aproveitavam os mitos conhecidos para a composição dos textos dramáticos a serem encenados nos festivais), mas nos importa aqui uma segunda acepção da expressão, ou seja, a possibilidade de considerá-la como estrutura narrativa da história. "Compor a fábula [...] [nesse sentido] é, para o autor dramático, estruturar as ações - motivações, conflitos, resoluções, desenlace - num espaço/tempo que é abstrato e construído a partir do tempo/espaço e do comportamento dos homens", destaca Pavis (2007, p. 157), que complementa:

\begin{abstract}
A fábula textualiza as ações que puderem ocorrer antes do início da peça ou que terão sequência após a conclusão da peça. Ela pratica uma seleção e uma ordenação dos episódios conforme um esquema mais ou menos rígido: o da dramaturgia clássica recomendará, por exemplo, respeitar a ordem cronológica e lógica dos acontecimentos: exposição, aumento de tensão, crise, nó, catástrofe e desenlace. (PAVIS, 2007, p. 157).
\end{abstract}

Há de se tomar o cuidado, ao refletir sobre a fábula, de não tomá-la simplesmente como o assunto da peça, como um material à disposição dos dramaturgos, que, a seu modo, deverão transformá-lo em dramaturgia: “A fábula é, portanto, nesta acepção, o conjunto de motivos que se pode reconstituir num sistema lógico ou dos acontecimentos ao qual o dramaturgo recorre". (PAVIS, 2007, p. 158). A noção de fábula que queremos destacar é a de “[...] instalação cronológica e lógica dos acontecimentos que constituem a armação da história representada". (PAVIS, 2007, p. 158). Tratando da fábula como estrutura narrativa, o estudioso francês afirma: "Mas a fábula se torna muitas vezes também uma noção de estrutura específica da história que a peça conta. Portanto, já se percebe aí a maneira pela 
qual o poeta [dramático] trata seu assunto e dispõe seus episódios particulares na intriga". (PAVIS, 2007, p. 158).

Pelos elementos que trouxemos à tona, nos cabe inferir que a fábula é a disposição dos acontecimentos, sejam eles advindos de uma fonte conhecida ou não, sobre a malha da construção dramatúrgica, momento em que o dramaturgo vai articular a ordenação dos episódios, principalmente se tratando de dramaturgia clássica, dentro de uma sequência que vai valorizar a sucessão dos fatos, numa lógica esperada e que resulte em um texto com arremates entre suas partes (exposição, aumento da tensão, crise, nó, catástrofe e desenlace, conforme já referimos). Na dramaturgia contemporânea, nem sempre todos os elementos que compõem a fábula vão estar presentes (pelo menos não de maneira potencializada), mas há que se respeitar uma construção que permita perceber esse viés herdado da dramaturgia clássica, sob pena de o texto, caso assim não consiga se articular, não constituir uma realização plena em dramaturgia.

Tratando das propriedades gerais da fábula, Pavis (2007) afirma que ela precisa ser resumível e transponível. No primeiro caso, trata-se de reduzi-la a algumas frases que descrevem suscintamente os acontecimentos. Resumi-la, sintetizá-la, é como um teste: de posse da fábula completa da peça, busca-se, como se a tirar a prova dos nove, resumi-la para verificar se tal propriedade está presente. No segundo caso, "Mudando a substância da expressão (cinema, conto, teatro, pintura), deve-se poder conservar o sentido da fábula". (PAVIS, 2007, p. 161). Se a fábula migrar para outra linguagem, ela conservará seus elementos principais: a película, com sua estética, produção e recepção tão particulares; o conto, que possui outra maneira de articular e apresentar os fatos; a encenação teatral (tomando a ideia de que ela existe antes no texto dramatúrgico); a pintura, que deverá dispor de recursos para que a fábula se construa e se sustente. A necessidade de a fábula ser transponível nos aponta para o número de sistemas artísticos que podem receber (por assim dizer) uma história gerada, gestada primeiramente nos moldes dramáticos. Podemos acrescentar a telenovela, a arte circense, a escultura, e como sinal dos nossos tempos, a literatura digital. Não estamos a falar dos arquivos em Portable Document Format (PDF) que se proliferam na rede com obras literárias, e sim de uma literatura feita com os recursos da Internet (imagem, palavra escrita e falada, som, movimento), que muitas vezes expõem o quanto a fábula dramatúrgica é transponível para outros sistemas artísticos. 


\section{Palavras finais}

A divisão que Pavis $(2011,2008)$ estabelece entre espetáculos com visão "textocentrista" e espetáculos com visão "cenocentrista" tem sua validade por nos apontar que não existe uma maneira única de lidar com o espetáculo teatral e com as relações que os seus elementos estabelecem. Nossa tendência é considerar que o espetáculo com a primeira visão é mais próximo do que temos escrito e publicado desde nossos primeiros textos sobre dramaturgia escrita, e, em especial, a tese que construímos em nosso curso de doutoramento. Para a nossa pesquisa, não buscamos um referencial teórico que embase a dramaturgia escrita para a leitura da criança somente em estudos de dramaturgia específicos para este público. Nosso estudo se potencializou ao passo em que analisarmos o corpus de pesquisa escolhido a partir de fundamentos teóricos que guiam os estudos de dramaturgia em geral, pois caso teríamos criando uma espécie de defasagem entre as teorias e o próprio corpus.

Nesse sentido, revisar os estudos de Pavis $(2007,2008,2011)$ se tornou uma prática importante, pois, além de recuperarmos as duas visões do espetáculo que o autor expõe e relacionarmos com outras questões, como a visão inovadora das rubricas no texto dramático apresentada por Ramos (1999), pudemos desenvolver, acreditamos que de maneira clara, alguns aspectos dos estudos teóricos do autor francês. $\mathrm{O}$ que fizemos, depois de discutirmos as duas visões do espetáculo teatral, foi ampliar o levantamento sugerido por Pavis (2011), o qual repetimos: a determinação da ação e dos actantes; as estruturas do espaço, do tempo e do ritmo; a articulação e o estabelecimento da fábula. A explicação de cada elemento citado, as relações que estabelecem entre si, e um ou outro diálogo com estudos já realizados constituíram este trabalho.

\section{Referências}

AGUIAR, Ramon Santana de. Espaço e memória: a construção de um espaço mnemônico na história do espetáculo. In: LIMA, Evelyn Furquim Werneck (Org.). Espaço e teatro: do edifício teatral à cidade como palco. Rio de Janeiro: 7 Letras, 2008. p. 213-238.

LOPES, Clarisse Mendes. 0 ensino da voz na formação do ator. Dissertação (Mestrado em Artes Cênicas). Universidade Federal do Estado do Rio de Janeiro: Centro de Letras e Artes, Programa de Pós-Graduação em Artes Cênicas, 2009. 
PAVIS. Patrice. Dicionário de teatro. Tradução de J. Guinsburg e Maria Lúcia Pereira. 3. ed. São Paulo: Perspectiva, 2007.

PAVIS. Patrice. Do texto para o palco: um parto difícil. In: PAVIS. Patrice. 0 teatro no cruzamento de culturas. Tradução de Nanci Fernandes. São Paulo: Perspectiva, 2008.

PAVIS. Patrice. A análise dos espetáculos: teatro, mímica, dança, teatro-dança, cinema. Tradução de Sérgio Sávia Coelho. 2. ed. São Paulo: Perspectiva, 2011.

RAMOS, Luiz Fernando. 0 parto de Godot e outras encenações imaginárias: a rubrica como poética de cena. São Paulo: Hucitec/Fapesp, 1999.

SILVA, Daniel Furtado Simões. O ator e o personagem: variações e limites no teatro contemporâneo. 235 f. Tese. (Doutorado em Artes Cênicas). Universidade Federal de Minas Gerais: Escola de Belas Artes, Programa de Pós-Graduação em Artes, 2013.

Recebido em: 21/10/2019

Aceito em: $12 / 03 / 2019$ 